\title{
PAGES pilot to chart new waters
}

Hubertus Fischer ${ }^{1}$ and Alan Mix², Co-Chairs, PAGES Scientific Steering Committee

\section{After 10 years of extraordinary service and success with PAGES, Executive Director Thorsten Kiefer moves on to even larger challenges at the Future Earth Global Hub in Paris.}

Thorsten began his scientific life as a paleoceanographer, with a PhD from the University of Kiel in 1997, followed by postdocs first in Kiel and then at University of Cambridge. While in the UK, Thorsten honed his leadership and diplomacy skills as well as a British sense of humor, all of which made his decade with PAGES, which started in 2005 when Thorsten became director of the PAGES International Project Office in Bern, both successful and fun.

2005 was a difficult year for PAGES; although the science was strong, funding was at risk. Jumping aboard, Thorsten grabbed the PAGES wheel and began to steer. His first task was to organize the $2^{\text {nd }}$ Open Science Meeting (OSM) in Beijing in August 2005. Following the Beijing OSM, Thorsten organized the 2009 and 2013 OSMs in Corvallis and Goa, and in the process made this four-yearly event a bright beacon in the global paleoscience calendar. Thorsten recognized the special needs of early-career researchers, and in 2009 he successfully launched the first Young Scientists Meeting alongside the OSM in Corvallis; this innovative model is now emulated by many other projects and societies.

Having righted the ship, Thorsten's next task was to chart a new course, guiding the development and implementation of
PAGES' new Science Structure in 2006. A clear structure of foci and cross-cutting themes became the channel through which PAGES has navigated during the last 10 years, launching 40 working groups that have yielded over 157 peer reviewed journal articles and 43 special issues. Under this structure, the PAGES community grew to more than 5,500 subscribers from 125 countries.

Yet another challenge came in the past two years, with PAGES required to change course again as its former guiding star, the International Geosphere Biosphere Program (IGBP), set and a new one rose in form of the transdisciplinary sustainability program Future Earth. Again through his steady guidance of the scientific community, Thorsten helped navigate the PAGES ship safely into this new harbor. With a newly defined science structure (www.pages-igbp.org/science/intro), and a new stronger relationship both with Future Earth and the World Climate Research Programme, PAGES is perfectly positioned to continue its leadership in paleoscience while helping to contribute to Future Earth's goal of accelerating the transformation to sustainable practices. During the transition process, Thorsten has helped communicate the unique insights that paleoscience can bring regarding the long-term changes in the Earth system and how these can be of benefit in preparing for the future. Building on Thorsten's legacy, PAGES will continue its tradition of openness and inclusion, and will remain a beacon that leads the world's community of paleoscientists to meet, collaborate, and advance a coordinated agenda for globally relevant paleoscience.

In September this year, after a decade spent transforming PAGES into a polished speedboat, Thorsten moved on to assume an even larger responsibility, piloting the supertanker that is the Future Earth Global Hub in Paris. Here he will find a new chance to navigate the shallows of early program implementation and to set the course for even larger scientific vistas. For PAGES this is a great loss, but it is also a great gain. Thorsten has left PAGES with a sturdy hull and wind in its sails, and we are reassured that his deep expertise and remarkable skills will provide a steady hand on the wheel of Future Earth, and that PAGES will be well understood within the larger context.

\section{AFFILIATIONS}

${ }^{1}$ Climate and Environmental Physics, University of Bern, Switzerland

${ }^{2}$ College of Earth, Ocean, and Atmospheric Sciences, Oregon State University, Corvallis USA

\section{CONTACT}

Hubertus Fischer: hubertus.fischer@climate.unibe.ch

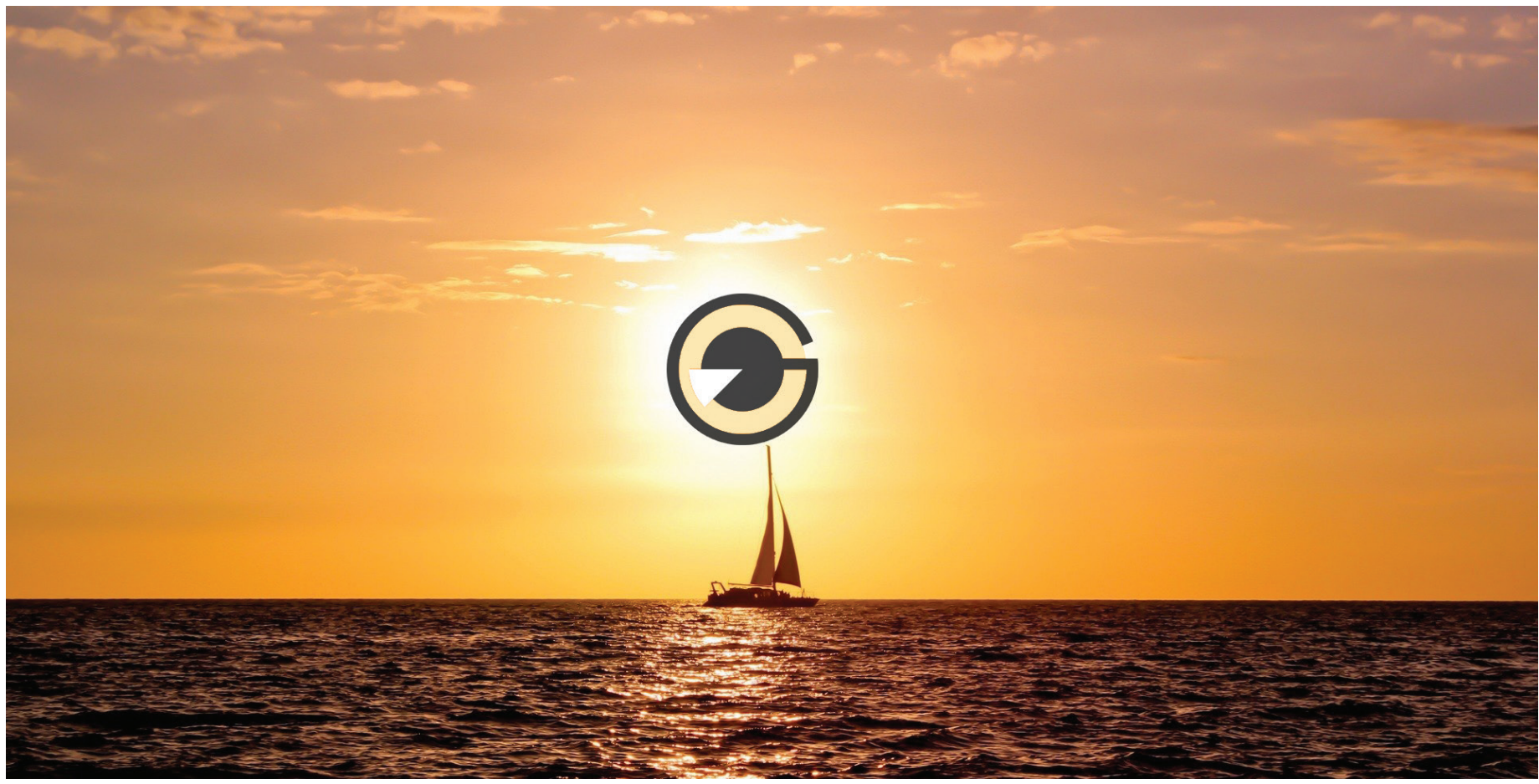

